Jarosław ZIÓŁKOWSKI ${ }^{1}$, Józef ŻUREK ${ }^{2}$, Aleksandra LĘGAS ${ }^{1}$, Joanna SZKUTNIK-ROGOŻ ${ }^{1}$, Mateusz OSZCZYPAŁA ${ }^{1}$, Krzysztof DOBRZYŃSKI ${ }^{1}$

${ }^{l}$ Military University of Technology (Wojskowa Akademia Techniczna)

${ }^{2}$ Air Force Institute of Technology (Instytut Techniczny Wojsk Lotniczych)

\title{
PLANNING SUPPLIES IN THE ENTERPRISE IN THE ASPECT OF RELIABILITY
}

\section{Planowanie dostaw w przedsiębiorstwie w aspekcie niezawodności}

\begin{abstract}
The article presents the example of material needs planning (MRP) methodology in a production company. The example assumes the production technology of three independent products $A, B$ and $C$ exhibiting structural modularity. For calculations, a methodology should be developed for describing products with such a structure that reflects the relationships of individual components used to prepare a delivery schedule. The Microsoft Excel spreadsheet was used as the calculation tool.
\end{abstract}

Keywords: reliability, delivery scheduling, product structure, planning

Streszczenie: $W$ artykule przedstawiono na przykładzie metodyke planowania potrzeb materiałowych (MRP) $w$ przedsiębiorstwie produkcyjnym. W przykładzie założono technologię wytwarzania trzech niezależnych wyrobów A, B i C wykazujacych modułowość strukturalną. Do obliczeń należy opracować metodykę opisu wyrobów o takiej strukturze odzwierciedlająca zależności poszczególnych elementów składowych, slużacych do sporzadzenia harmonogramu dostaw. Jako narzędzie stużace do obliczeń wykorzystano arkusz kalkulacyjny MS Excel.

Słowa kluczowe: niezawodność, harmonogramowanie dostaw, struktura wyrobu, planowanie 


\section{Introduction}

The specificity of industrial enterprises is the processing of raw materials for production into finished products as a result of the manufacturing process. This process is almost always accompanied by a change in the form, shape and often properties of the product referred to as the final product. This publication presents the methodology for describing products with a modular structure and then, using it, a delivery schedule was developed that takes into account individual customer orders. Timely execution of assembly tasks, precise determination of inventory levels, determination of production batch sizes as well as synchronization and control of the manufacturing and assembly process affect the reliability of the production order planning process.

Material Requirement Planning (MRP) in the subject literature is ambiguously interpreted. For example C. Bozarth and R.B. Handfield defines it as: "a planning process that allows you to translate an overarching production plan into planned orders for parts and components needed to manufacture products whose completion has been included in an overarching plan"[1]. The concept of MRP is slightly differently perceived by B. Śliwczyński, who states that: “(...)material requirement planning covers every element of the final product, at each stage of the production process and defines the schedule of material demand, resulting from the range, size and deadline of the production batch. In accordance with the MRP method, delivery times for materials and elements necessary to manufacture the finished product are calculated, according to the main production schedule. As a result of material requirement planning, a delivery schedule is developed that is the basis for material supply planning" [7]. In contrast, D. Waters in his book stated that: “(...)material requirement planning (MRP) uses the main production plan to plan the supply of materials. The extension of the main production plan makes it possible to plan deliveries of materials exactly when they are needed" [8]. On the other hand, S. Krawczyk [2] positions MRP in the process of servicing a production company, and therefore refers them to, among others to the level of customer service. Therefore, he draws attention to the aspect concerning reliability of supply, which should be understood in a slightly narrower sense as the timeliness of task implementation. The concept of reliability of supply related to the enterprise can and should be considered on many levels. For example, reliability of supply can be created by: no damage, suitability, timeliness, compliance, completeness, etc. T. Nowakowski $[4,5]$ indicates that the reliability of delivery consists of: timely delivery, completeness of the order and delivery / receipt of the item without damage. J. Żurek [3, 12] shows a close relationship between reliability and readiness and relates these concepts to the processes of operation of technical facilities and systems. In the case of the reliability of inventory control systems, it indicates that one of the basic methods of supply reliability is to maintain excess understood as a safety stock. In addition, the author differentiates the level of inventory depending on the criterion of costs (prices). It states that the stocks of cheap items can be kept at a high level of sufficiency, while the stocks of expensive items can be kept at a low or zero level of sufficiency. Very expensive items are often bought only as a result of demand [8]. S. Werbińska-Wojciechowska [10] also points to the time 
redundancy in the aspect of assessing the availability of resources in the enterprise logistics system, paying attention to the issue of the temporary availability of resources [9].

The MRP system improves inventory management and facilitates the creation of demand plans for raw materials and materials needed for production, for which demand depends on market needs. They form the production schedule, defined in calendar time, taking into account both the labor-intensive assembly, as well as delivery times of the components. Its correct performance therefore affects the reliability of supplies understood (in a narrow scope) as the timeliness of production orders. The basic information of the MRP system consists of information streams (fig. 1), which contain:

- main production schedule;

- product structure;

- main stock collection.

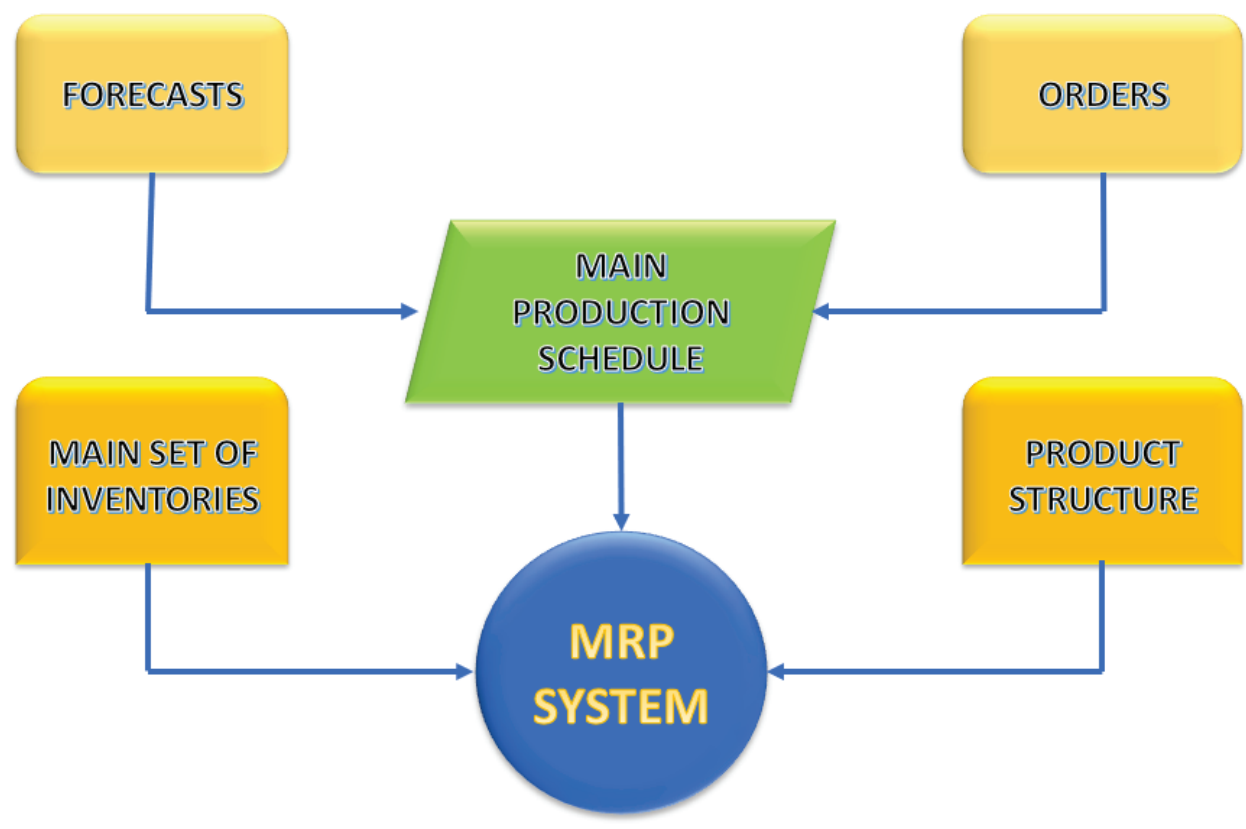

Fig. 1. Information streams supplying the MRP system $[1,2,6,7,8,11]$

As can be seen from fig. 1, the information streams making up the MRP system form: the main production schedule, which is created in the long term on the basis of sales forecasts, while in the shorter time horizon is confirmed by orders from customers. The second stream is the main set of inventories, extended by the times of assembly and delivery activities, while the third is the modular product structure. The above described components will be used for practical preparation of the delivery schedule. 


\section{Delivery schedule in practice}

The main component of the MRP system is the main production schedule, which contains orders from customers regarding the required number of products and the time of order processing. In this context, a properly prepared schedule ensures reliability understood in a narrower sense as timely deliveries. To prepare it, you also need the structure of products A, B and C (figs. 2-4) and the way of its description, which will be used to calculate individual components of the MRP system.

The final product presented consists structurally of products A, B and C, which contain repeating (at least twice) fragments of the structure called modules.

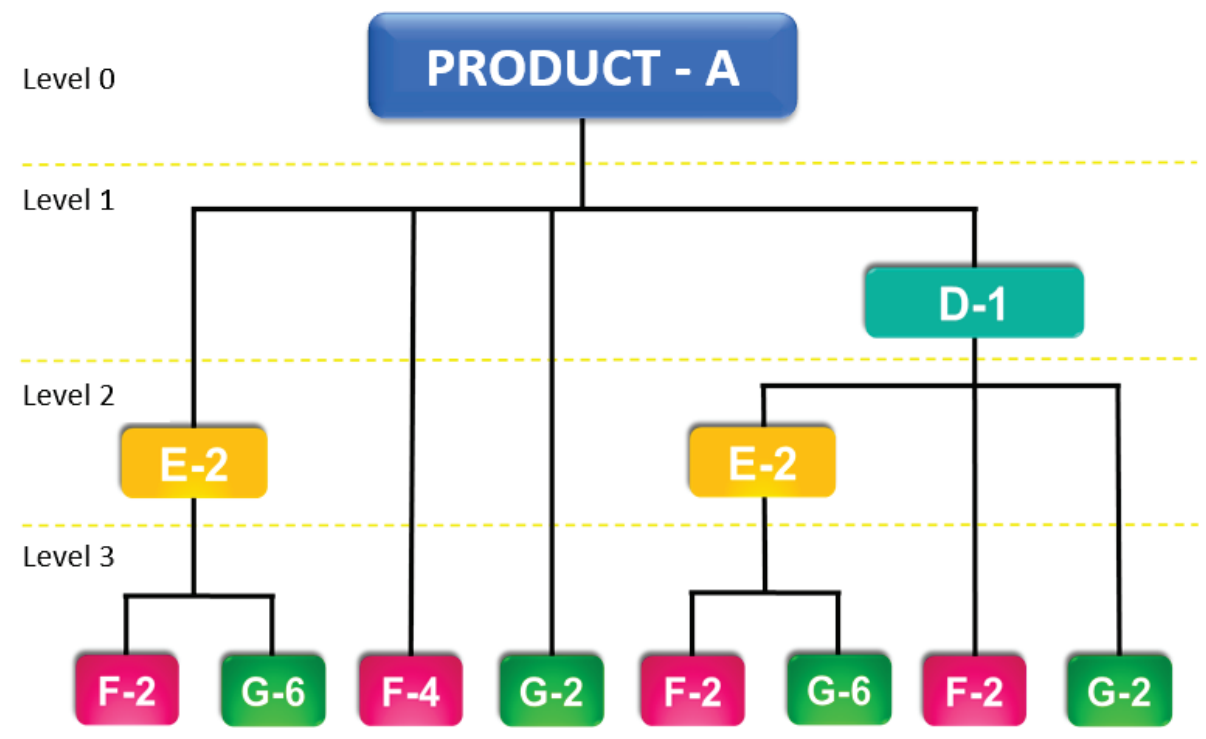

Fig. 2. Product - A structure

As can be seen from fig. 2, two types of functional modules can be distinguished in the structure of product A:

- first order module D-1 (consists of the said second order module E-2 and two elements marked as F and two elements of type $\mathrm{G}$ );

- second-order module E-2 (consists of two F-type elements and six G-type elements).

In addition, product $\mathrm{A}$ consists of elements placed in the structure on three functional levels. At the first level there is a D-1 module, the second level represents the E-2 module, while at the third level there are structurally independent elements of the F-2, F-4 and G-2 and G-6 types. 


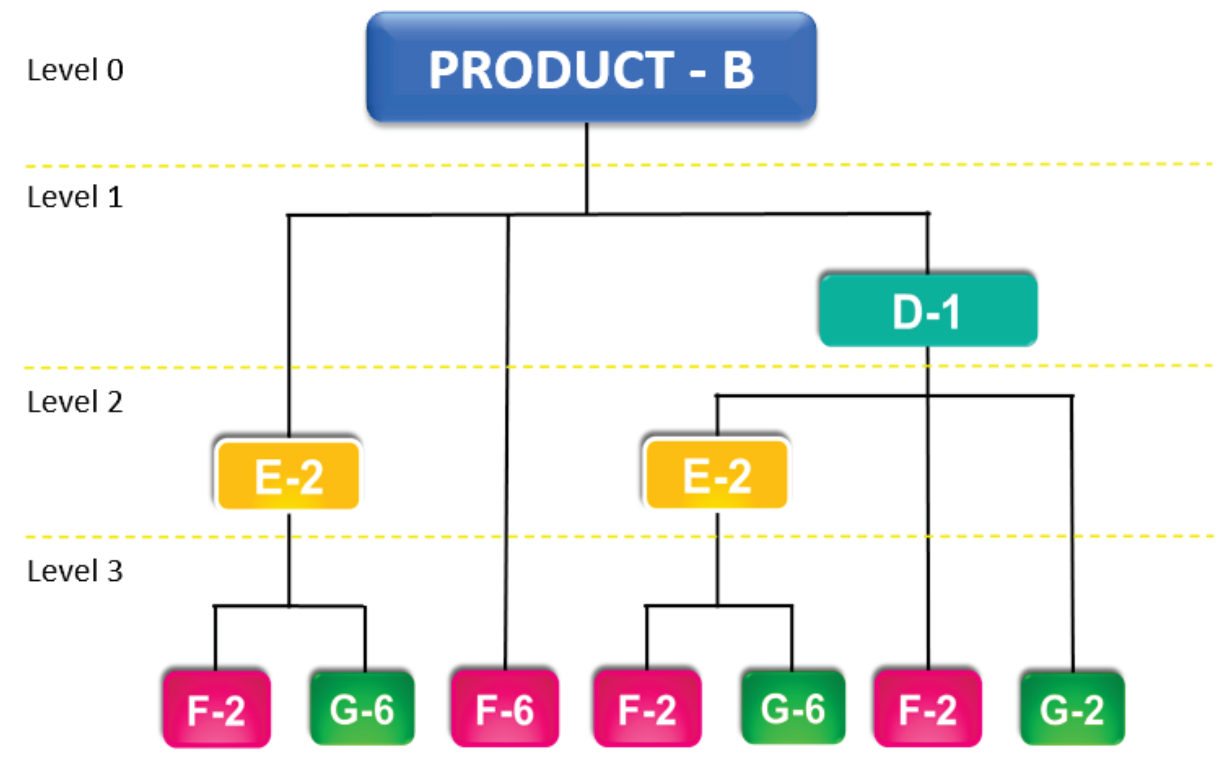

Fig. 3. Product - B structure

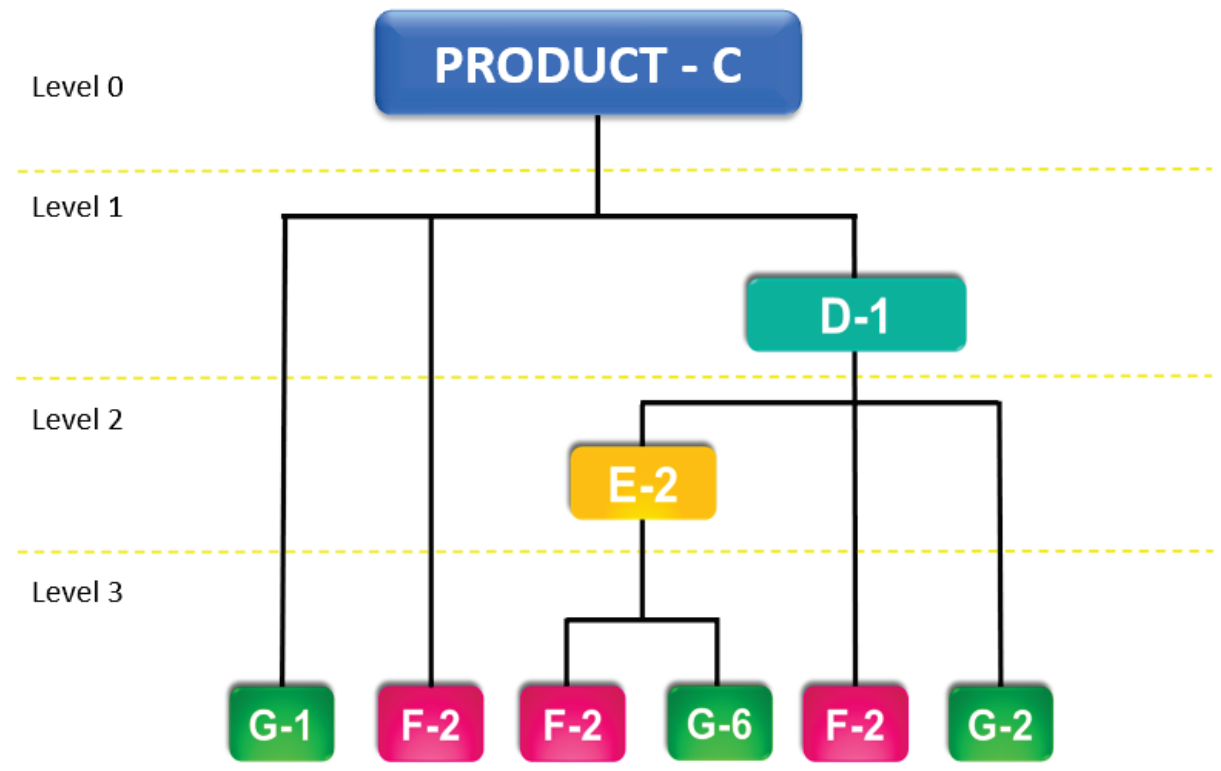

Fig. 4. Product $-\mathrm{C}$ structure 
The structure of products $\mathrm{B}$ and $\mathrm{C}$ is considered by analogy (figs. 3-4). It should be borne in mind that products $\mathrm{A}, \mathrm{B}$ and $\mathrm{C}$ are located at the same level 0 . They are therefore structurally independent of each other, but together they form a common final product. The modularity of both products discussed above causes a specific description of their structure, used for calculations in the delivery schedule (MRP). Below is the description methodology, according to which such a schedule should be performed starting from level 0 and ending on level 3.

Analyzing figs. 2-4 it should be stated that in the structure of products A, B and C forming the final product, at the first level there is one D-1 type module (this is the so-called first order module). At the second level of the structure there is the E-2 module (this is the so-called second order module). The methodology for describing such a structure is as follows:

- products A, B and C are located at the same level (level 0) and have no structural connections between them and are therefore not subject to description;

- at level 1 in both products there is a D-type module, on the second there is an E-type module, and on the third there are structure-independent $\mathrm{F}$ and $\mathrm{G}$ elements;

- the fact that module $\mathrm{D}$ is found in products $\mathrm{A}, \mathrm{B}$ and $\mathrm{C}$ is written as follows: $\mathrm{D}(\mathrm{A}, \mathrm{B}, \mathrm{C})$;

- at the second level in the structure of products there is a module type E-2, with respect to the structure of products $\mathrm{A}, \mathrm{B}$ and $\mathrm{C}$ has a slightly different location, namely in the case of products A and B it is directly subordinated to them (figs. 2 and 3, level 0 ) and is an integral part of the D-1 module, while with regard to product $\mathrm{C}$ it is only an integral part of the $\mathrm{D}-1$ module (level 2), this fact should be described as $\mathrm{E}(2 \mathrm{~A}, 2 \mathrm{~B}, 2 \mathrm{D})$;

- at the last level (level 3) there are elements that should be described analogously according to the principles presented above, and therefore: $\mathrm{F}(4 \mathrm{~A}, 6 \mathrm{~B}, 2 \mathrm{C}, 2 \mathrm{D}, \mathrm{E})$ and $\mathrm{G}(2 \mathrm{~A}, \mathrm{C}, 2 \mathrm{D}, 3 \mathrm{E})$.

The above description methodology will be used for calculations in the material requirement plan (MRP).

Table 1 shows the planned production of products $\mathrm{A}$ and $\mathrm{B}$, module type $\mathrm{D}$ and the element marked as E.

Table 1

\section{Main production schedule}

\begin{tabular}{||l|l|l|l|l|l|l|l|c|c|c|c|c|c|c|c|c||}
\hline \multirow{2}{*}{ SPECIFICATION } & \multicolumn{10}{|c||}{ DATES (WEEKS) } \\
\cline { 2 - 16 } & 3 & 4 & 5 & 6 & 7 & 8 & 9 & 10 & 11 & 12 & 13 & 14 & 15 & 16 & 17 & 18 \\
\hline Product A & & & & & & & & 1800 & & & & 650 & & & & 600 \\
\hline Product B & & & & & & & & 700 & & & & 460 & & & & 310 \\
\hline Product C & & & & & & & & 850 & & & & 700 & & & & 250 \\
\hline Module D & & & & & 250 & & & & & & 400 & & & & & \\
\hline
\end{tabular}


table 1 cont.

\begin{tabular}{||l|c|c|c|c|c|c|c|c|c|c|c|c|c|c|c|c||}
\hline \multirow{2}{*}{ SPECIFICATION } & \multicolumn{10}{|c||}{ DATES (WEEKS) } \\
\cline { 2 - 15 } & 3 & 4 & 5 & 6 & 7 & 8 & 9 & 10 & 11 & 12 & 13 & 14 & 15 & 16 & 17 & 18 \\
\hline Module E & & & & & & & & 450 & & & & 280 & & & & 320 \\
\hline Element F & & & & & & & & 170 & & & & 330 & & & & 150 \\
\hline Element G & & & 300 & & & & & & & & 250 & & & & & \\
\hline
\end{tabular}

Table 2 presents the company's inventory of individual products, modules and components for the first and seventh weeks. They are used to calculate the net demand, which is defined as the difference between gross demand and available inventory.

Table 2

\section{Enterprise inventory}

\begin{tabular}{|c|c|c|c|c|c|c|c|c|c|c|c|c|c|c|c|c|}
\hline \multicolumn{17}{|c|}{ MAIN SET OF INVENTORIES } \\
\hline \multirow{2}{*}{ SPECIFICATION } & \multicolumn{16}{|c|}{ DATES (WEEKS) } \\
\hline & 3 & 4 & 5 & 6 & 7 & 8 & 9 & 10 & 11 & 12 & 13 & 14 & 15 & 16 & 17 & 18 \\
\hline Product A & & 70 & & & & & & & 30 & & & 250 & & & & \\
\hline Product B & & 200 & & & & & & & 80 & & & 120 & & & & \\
\hline Product $\mathrm{C}$ & & 50 & & & & & & & 20 & & & 340 & & & & \\
\hline Module D & & 100 & & & & & & & 30 & & & 90 & & & & \\
\hline Module E & & 70 & & & & & & & 70 & & & 500 & & & & \\
\hline Element F & & 170 & & & & & & & 50 & & & 3400 & & & & \\
\hline Element $\mathrm{G}$ & & 400 & & & & & & & 80 & & & 3200 & & & & \\
\hline
\end{tabular}

Table 3 presents delivery times for products, modules and components that allow you to determine the exact moment so as to ensure continuity of production and efficient use of available resources.

Table 3

\section{Delivery times}

\begin{tabular}{|c|c|}
\hline \multicolumn{2}{|c|}{ DELIVERY TIME } \\
\hline Product A & 2 \\
\hline Product B & 2 \\
\hline Product C & 2 \\
\hline Module D & 1 \\
\hline Module E & 1 \\
\hline Element F & 1 \\
\hline Element G & 1 \\
\hline
\end{tabular}


Table 4 below presents the material requirement plan (MRP), for the preparation of which the data presented in tables 1-3 were used. To calculate the gross demand, the description methodology developed above, characteristic of the structure of products $\mathrm{A}, \mathrm{B}$ and $\mathrm{C}$ showing modularity, was used. This methodology applies to the description of modules designated as D-1 and E-2 and elements referred to as F and G, and therefore refers to the components placed at levels 1-3 of the product structure (see figs. 1, 2 and 3).

Table 4

Material requirement plan for products $A, B$ and $C$

\begin{tabular}{|c|c|c|c|c|c|c|c|c|c|c|c|c|c|c|c|c|}
\hline \multicolumn{17}{|c|}{ MRP } \\
\hline Dates (weeks) & 3 & 4 & 5 & 6 & 7 & 8 & 9 & 10 & 11 & 12 & 13 & 14 & 15 & 16 & 17 & 18 \\
\hline Product A - gross demand & & & & & & & & 1800 & & & & 650 & & & & 600 \\
\hline Reserve available & & 70 & 70 & 70 & 70 & 70 & 70 & 70 & 30 & 30 & 30 & 280 & & & & \\
\hline Net demand & & & & & & & & 1730 & & & & 370 & & & & 600 \\
\hline Order (production order) & & & & & & 1730 & & & & 370 & & & & 600 & & \\
\hline Product B - gross demand & & & & & & & & 700 & & & & 460 & & & & 310 \\
\hline Reserve available & & 200 & 200 & 200 & 200 & 200 & 200 & 200 & 80 & 80 & 80 & 200 & & & & \\
\hline Net demand & & & & & & & & 500 & & & & 260 & & & & 310 \\
\hline Order (production order) & & & & & & 500 & & & & 260 & & & & 310 & & \\
\hline Product C - gross demand & & & & & & & & 850 & & & & 700 & & & & 250 \\
\hline Reserve available & & 50 & 50 & 50 & 50 & 50 & 50 & 50 & 20 & 20 & 20 & 360 & & & & \\
\hline Net demand & & & & & & & & 800 & & & & 340 & & & & 250 \\
\hline Order (production order) & & & & & & 800 & & & & 340 & & & & 250 & & \\
\hline Product D - gross demand & & & & & 250 & 3030 & & & & 970 & 400 & & & 1160 & & \\
\hline Reserve available & & 100 & 100 & 100 & 100 & & & & 30 & 30 & & 90 & 90 & 90 & & \\
\hline Net demand & & & & & 150 & 3030 & & & & 940 & 400 & & & 1070 & & \\
\hline Order (production order) & & & & 150 & 3030 & & & & 940 & 400 & & & 1070 & & & \\
\hline Product E - gross demand & & & & 300 & 6060 & 4460 & & 450 & 1880 & 2060 & & 280 & 2140 & 1820 & & 320 \\
\hline Reserve available & & 70 & 70 & 70 & & & & & 70 & & & 500 & 220 & & & \\
\hline Net demand & & & & 230 & 6060 & 4460 & & 450 & 1810 & 2060 & & & 1920 & 1820 & & 320 \\
\hline Order (production order) & & & 230 & 6060 & 4460 & & 450 & 1810 & 2060 & & & 1920 & 1820 & & 320 & \\
\hline Product F-gross demand & & & 230 & 6360 & 10520 & 11520 & 450 & 1980 & 3940 & 4520 & & 2250 & 3960 & 4760 & 320 & 150 \\
\hline Reserve available & & 170 & 170 & & & & & & 50 & & & 3400 & 1150 & & & \\
\hline Net demand & & & 60 & 6360 & 10520 & 11520 & 450 & 1980 & 3890 & 4520 & & & 2810 & 4760 & 320 & 150 \\
\hline Order (production order) & & 60 & 6360 & 10520 & 11520 & 450 & 1980 & 3890 & 4520 & & & 2810 & 4760 & 320 & 150 & \\
\hline Product G - gross demand & & & 990 & 18480 & 19440 & 4260 & 1350 & 5430 & 8060 & 1880 & 250 & 5760 & 7600 & 1450 & 960 & \\
\hline Reserve available & & 400 & 400 & & & & & & 80 & & & 3200 & & & & \\
\hline Net demand & & & 590 & 18480 & 19440 & 4260 & 1350 & 5430 & 7980 & 1880 & 250 & 2560 & 7600 & 1450 & 960 & \\
\hline Order (production order) & & 590 & 18480 & 19440 & 4260 & 1350 & 5430 & 7980 & 1880 & 250 & 2560 & 7600 & 1450 & 960 & & \\
\hline
\end{tabular}

The presented material needs plan has been made for a time horizon covering 3-18 weeks. Gross demand for products A and B were submitted in weeks 7-18. After taking delivery times and assembly times into account, the internal orders generated actually covered a time range of 1-4 weeks. It is associated with the so-called reverse planning and bill of material related to the structure of the product.

\section{Conclusions}

The purpose of this article was to develop a description methodology for modular products and to apply it to production scheduling. The planned goal has been achieved and the article shows how to plan production for products with modular characteristics and determine the moment of their order so as to maintain the continuity and rhythm of the 
production process. This is extremely important from the point of view of timely execution of external orders (independent demand), and therefore affects the reliability of delivery. The presented methodology of conduct eliminates errors, reduces the level of maintained inventories, enables full control of individual production stages, improves the use of available resources and synchronizes the processes of ordering and delivering materials with production needs. The methodology of conduct was developed in 1957 by APICS (American Production and Inventory Control Society), its special development occurred in the seventies and eighties of the twentieth century. It is dedicated to variable demand, characterized by irregularity, and the manufacturing company produces products on a mass scale. For this reason, it should first be referred to mass production or stream production, secondly to unit production or a combination of the types mentioned above.

\section{References}

1. Bozarth C., Handfield R.B.: Wprowadzenie do zarządzania operacjami i łańcuchem dostaw. Helion, Gliwice 2007.

2. Krawczyk S. (ed.): Logistyka. Teoria i praktyka. t. 2. Difin, Warszawa 2011.

3. Niziński S., Żurek J.: Logistyka ogólna. WKiŁ, Warszawa 2011.

4. Nowakowski T.: Niezawodność systemów logistycznych. OWPW, Wrocław 2011.

5. Nowakowski T.: Reliability model of combined transportation system. [in:] Probabilistic Safety Assessment and Management. Spitzer C., Schmocker U., Dang V.N. (ed.). Springer, London 2004.

6. Skowronek Cz., Sarjusz-Wolski Z.: Logistyka w przedsiębiorstwie. PWE, Warszawa 2012.

7. Śliwczyński B.: Planowanie logistyczne. ILiM, Poznań 2008.

8. Tomaszewska J., Woch M., Zieja M.: Analysis of the time between failures of aircrafts, 2nd International Conference on System Reliability and Safety, ICSRS 2017, Volume 2018-January, 29 January 2018.

9. Ważny M., Stepień S., Zieja M.: Outline of a method for estimating the durability of components or device assemblies while maintaining the required reliability level. Eksploatacja i Niezawodnosc Vol. 20, Iss. 2, 2018.

10. Werbińska-Wojciechowska S.: Time resource problem in Logistics systems dependability modeling. Eksploatacja i Niezawodność - Maintenance and Reliability, 15(4), 2013.

11. Zięba M., Ziółkowski J.: System planowania potrzeb materiałowych (MRP) w przedsiębiorstwie produkcyjnym. Biuletyn Wojskowej Akademii Technicznej nr 3/2012.

12. Żurek J., Zieja M., Ziółkowski J.: Reliability of supplies in a manufacturing enterprise. Safety and Reliability - Theory and Applications, Taylor \& Francis Group, London 2018. 


\section{PLANOWANIE DOSTAW W PRZEDSIĘBIORSTWIE W ASPEKCIE NIEZAWODNOŚCI}

\section{Wprowadzenie}

Specyfika funkcjonowania przedsiębiorstw przemysłowych polega na przetwarzaniu, w wyniku procesu wytwórczego, surowców do produkcji w wyroby gotowe. Procesowi temu niemal zawsze towarzyszy zmiana postaci, kształtu oraz często właściwości wyrobu określanego jako produkt finalny. W niniejszej publikacji zaprezentowano metodykę opisu wyrobów o strukturze modułowej oraz opracowany z jej zastosowaniem harmonogram dostaw uwzględniający zamówienia poszczególnych klientów. Terminowa realizacja zadań montażowych, precyzyjne określenie poziomu zapasów, określenie wielkości partii produkcyjnych oraz synchronizacja i kontrola procesu wytwórczo-montażowego wpływają bowiem na niezawodność procesu planowania zleceń produkcyjnych.

Problematyka planowania potrzeb materiałowych, (ang. material requirement planning - MRP) w literaturze przedmiotu jest niejednoznacznie interpretowana. Przykładowo, C. Bozarth i R.B. Handfield określają ją jako: „proces planistyczny pozwalający przełożyć nadrzędny plan produkcji na planowane zamówienia na części i komponenty potrzebne do wyprodukowania wyrobów, których ukończenie zostało ujęte w planie nadrzędnym" [1]. Nieco inaczej koncepcję MRP postrzega B. Śliwczyński, który stwierdza, że: „(...) planowanie potrzeb materiałowych obejmuje każdy element wyrobu finalnego, w każdej fazie procesu produkcji i określa harmonogram zapotrzebowania materiałowego, wynikający $\mathrm{z}$ asortymentu, wielkości $\mathrm{i}$ terminu wykonania partii produkcyjnej. Zgodnie $\mathrm{z}$ metodą MRP obliczane są terminy dostawy materiałów i elementów koniecznych do wytworzenia wyrobu gotowego, według głównego harmonogramu produkcji. W wyniku planowania potrzeb materiałowych opracowany jest harmonogram dostaw, będący podstawą planowania zaopatrzenia materiałowego" [7]. Natomiast według D. Watersa „(...) planowanie zapotrzebowania materiałowego (MRP) posługuje się głównym planem produkcji w celu zaplanowania zaopatrzenia w materiały. Rozszerzenie głównego planu produkcji umożliwia zaplanowanie dostaw materiałów dokładnie w momencie, kiedy są one potrzebne" [8]. Z kolei S. Krawczyk [2] pozycjonuje MRP w procesie obsługi przedsiębiorstwa produkcyjnego, a zatem odnosi je m.in. do poziomu obsługi klienta. Zwraca uwagę na aspekt dotyczący niezawodności dostaw, którą należy rozumieć w nieco węższym znaczeniu jako terminowość realizacji zadań. Pojęcie niezawodności dostaw odniesione do przedsiębiorstwa można i należy rozpatrywać wielopłaszczyznowo. Na przykład niezawodność dostaw mogą tworzyć: brak uszkodzeń, 
odpowiedniość, terminowość, zgodność, kompletność itp. T. Nowakowski [4,5] twierdzi, że na niezawodność dostawy składają się: terminowa jej realizacja, kompletność realizacji zamówienia oraz wydanie/otrzymanie towaru bez uszkodzeń. J. Żurek [3,12] wykazuje ścisły związek niezawodności z gotowością i odnosi te pojęcia do procesów eksploatacji obiektów i systemów technicznych. W przypadku niezawodności systemów dotyczących sterowania zapasami podkreśla, że jedną z podstawowych metod niezawodności dostaw jest utrzymywanie nadmiaru rozumianego jako zapas bezpieczeństwa. Dodatkowo różnicuje poziom zapasów w zależności od kryterium kosztów (ceny). Stwierdza, że zapasy tanich elementów mogą być utrzymywane na dużym poziomie wystarczalności, natomiast zapas elementów drogich na małym lub zerowym poziomie wystarczalności. Elementy bardzo drogie są często kupowane wyłącznie w wyniku zaistnienia popytu [8]. S. Werbińska-Wojciechowska [10] wskazuje również na nadmiarowość czasową w aspekcie oceny dostępności zasobów systemu logistycznego przedsiębiorstw, zwracając uwagę na problematykę czasowej dyspozycyjności zasobów [9].

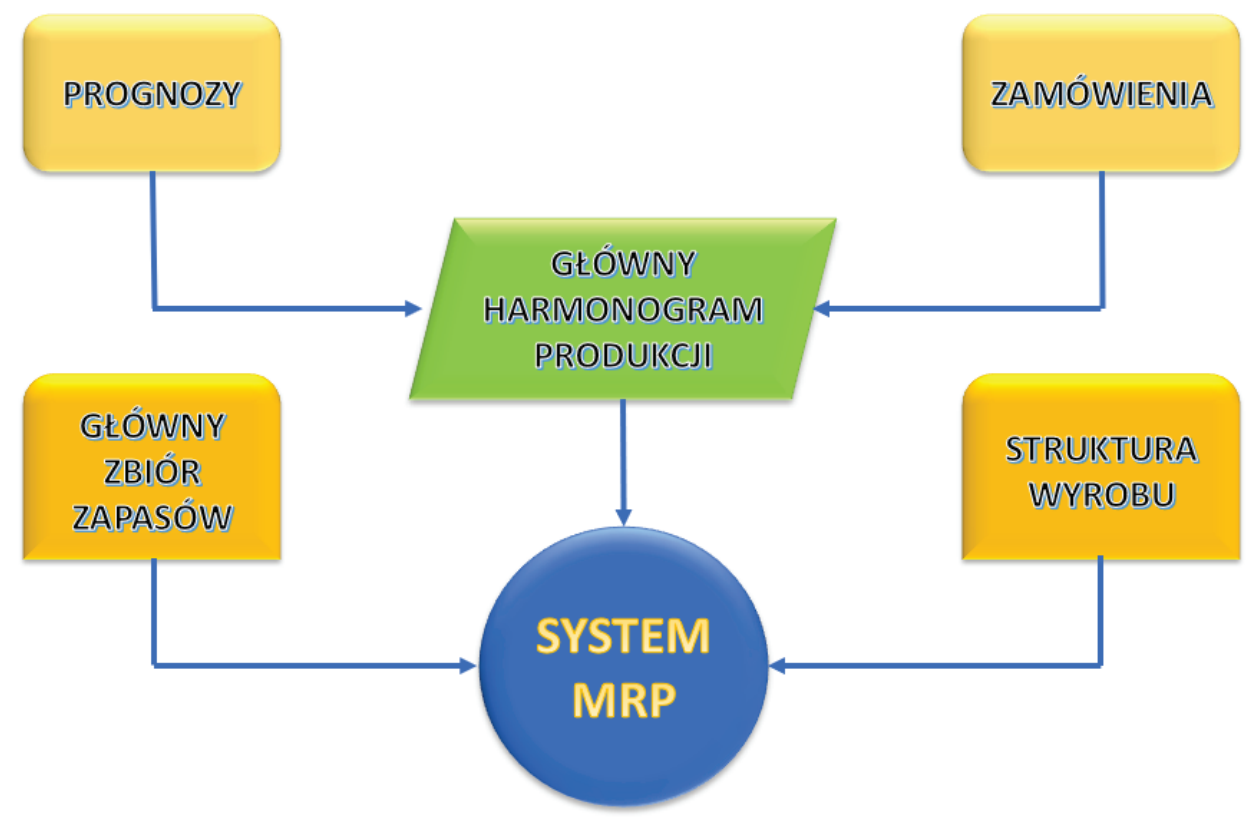

Rys. 1. Strumienie informacyjne zasilające system MRP [1,2,6,7,8,11]

System MRP usprawnia zarządzanie zapasami i ułatwia tworzenie planów zapotrzebowania na surowce i materiały potrzebne do produkcji, na które popyt jest uzależniony od potrzeb rynkowych. To właśnie one tworzą harmonogram produkcji, zdefiniowany w czasie kalendarzowym, uwzględniający zarówno pracochłonność montażu, jak również czasy dostaw elementów składowych. Jego poprawne wykonanie wpływa 
zatem na niezawodność dostaw rozumianą (w wąskim zakresie) jako terminowość wykonania zleceń produkcyjnych. Informacje podstawowe systemu planowania potrzeb materiałowych (MRP) tworzą strumienie informacyjne (rys. 1), w zbiorze których znajdują się:

- główny harmonogram produkcji,

- struktura wyrobu,

- główny zbiór zapasów.

Jak wynika z rys. 1, strumienie informacyjne składające się na system MRP tworzą: główny harmonogram produkcji, który powstaje w perspektywie długoterminowej na bazie prognoz dotyczących sprzedaży, natomiast w krótszym horyzoncie czasowym jest potwierdzany zamówieniami pochodzącymi od klientów. Drugim strumieniem jest główny zbiór zapasów, rozszerzony o czasy realizacji czynności montażowo-dostawczych, natomiast trzecim modułowa struktura wyrobu. Powyżej opisane elementy składowe zostaną wykorzystane do sporządzenia harmonogramu dostaw.

\section{Harmonogramowanie dostaw w praktyce}

Zasadniczą składową systemu MRP tworzy główny harmonogram produkcji, który zawiera zamówienia pochodzące od klientów, dotyczące wymaganej ilości wyrobów oraz czasu realizacji zamówień. W tym kontekście prawidłowo sporządzony harmonogram zapewnia niezawodność rozumianą w węższym zakresie jako terminowość dostaw. Do jego sporządzenia potrzebna jest ponadto struktura wyrobów A, B i C (rys. 2-4) oraz sposób jej opisu, który zostanie wykorzystany do kalkulacji poszczególnych składowych systemu MRP.

Zaprezentowany wyrób finalny składa się pod względem strukturalnym z produktów A, B oraz C, które zawierają powtarzające się (co najmniej dwukrotnie) fragmenty struktury, zwane modułami.

Jak wynika z rys. 2, w strukturze produktu A można wyróżnić dwa rodzaje modułów funkcjonalnych:

- $\quad$ moduł I rzędu D-1 (składa się ze wspomnianego modułu II rzędu E-2 oraz dwóch elementów oznaczonych jako F oraz dwóch elementów typu G);

- moduł II rzędu E-2 (składa się z dwóch elementów typu F oraz sześciu elementów typu G.

Ponadto produkt A składa się z elementów umieszczonych w strukturze na trzech poziomach funkcjonalnych. Na pierwszym poziomie występuje moduł typu D-1, drugi poziom reprezentuje moduł E-2, natomiast na trzecim znajdują się niezależne pod względem strukturalnym elementy typu F-2, F-4 oraz G-2 i G-6. 


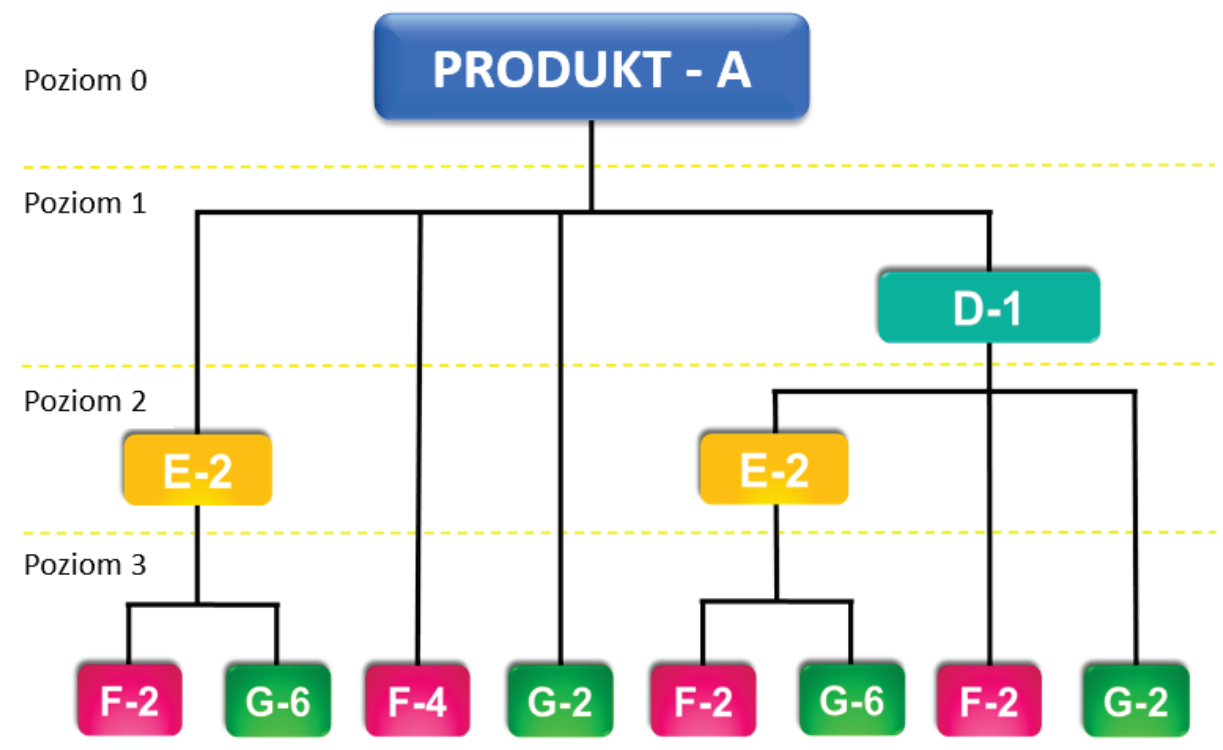

Rys. 2. Struktura produktu A

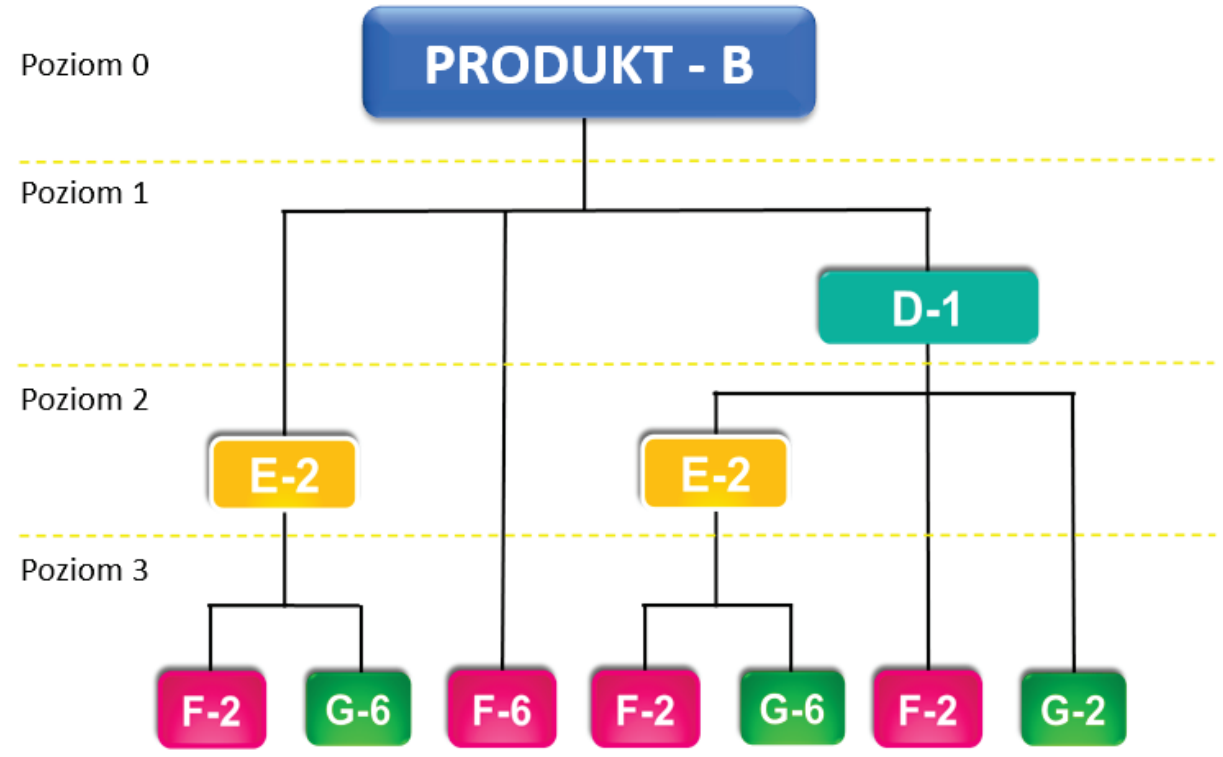

Rys. 3. Struktura produktu B 


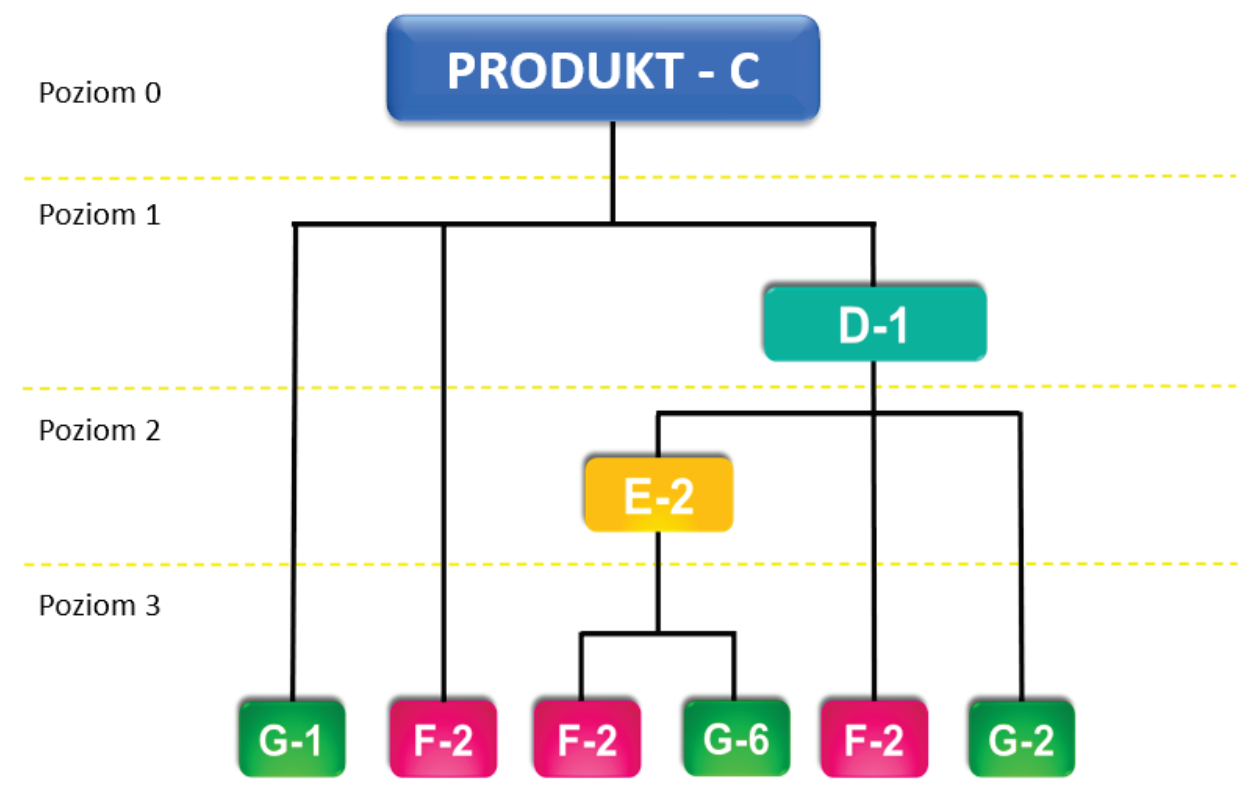

Rys. 4. Struktura produktu C

Poprzez analogię rozpatruje się strukturę produktów B i C (rys. 3-4). Należy mieć na uwadze, że wyroby A, B i C ulokowane na tym samym poziomie 0 . Są one zatem wobec siebie niezależne pod względem strukturalnym, natomiast łącznie tworzą wspólny produkt finalny. Omówiona powyżej modułowość obu wyrobów powoduje specyficzny opis ich struktury, wykorzystywany do obliczeń w harmonogramie dostaw (MRP). Poniżej zaprezentowano metodykę opisu, zgodnie z którą należy taki harmonogram wykonywać, zaczynając od poziomu 0 , a kończąc na poziomie 3 .

Analizując rys. 2-4, należy stwierdzić, że w strukturze produktów A, B i C tworzących wyrób finalny na pierwszym poziomie znajduje się jeden moduł typu D-1 (jest to tzw. moduł pierwszego rzędu). Na drugim poziomie struktury występuje moduł E-2 (jest to moduł tzw. drugiego rzędu). Metodyka opisu takiej struktury jest następująca:

- produkty A, B oraz C są usytuowane na tym samym poziomie (poziom 0) i nie ma między nimi powiązań strukturalnych, a zatem nie podlegają opisowi;

- na poziomie $1 \mathrm{w}$ obu wyrobach występuje moduł typu $\mathrm{D}$, na drugim moduł typu $\mathrm{E}$, a na trzecim niepodzielne pod względem struktury elementy typu F oraz G;

- fakt, że moduł D znajduje się w produktach A, B i C zapisuje się następująco: $\mathrm{D}(\mathrm{A}, \mathrm{B}, \mathrm{C})$;

- na drugim poziomie w strukturze wyrobów znajduje się moduł typu E-2, przy czym w odniesieniu do struktury produktów A, B i C ma nieco inną lokalizację, mianowicie w przypadku produktów A i B jest on bezpośrednio podporządkowany pod nie (rys. 2 i 3, poziom 0 ) oraz stanowi integralny element modułu typu D-1, 
natomiast $\mathrm{w}$ odniesieniu do produktu $\mathrm{C}$ stanowi tylko część integralną modułu typu D-1 (poziom 2), fakt ten należy opisać jako E(2A,2B,2D);

- na ostatnim poziomie (3) znajdują się elementy, które należy opisać analogicznie według zasad przedstawionych powyżej, a zatem: $\mathrm{F}(4 \mathrm{~A}, 6 \mathrm{~B}, 2 \mathrm{C}, 2 \mathrm{D}, \mathrm{E})$ oraz $\mathrm{G}(2 \mathrm{~A}, \mathrm{C}, 2 \mathrm{D}, 3 \mathrm{E})$.

Powyższa metodyka opisu zostanie wykorzystana do obliczeń w planie potrzeb materiałowych (MRP).

Tabela 1 przedstawia zaplanowaną produkcję wyrobów A i B, modułu typu D oraz elementu oznaczonego jako E.

Tabela 1

Glówny harmonogram produkcji

\begin{tabular}{|c|c|c|c|c|c|c|c|c|c|c|c|c|c|c|c|c|}
\hline \multirow{2}{*}{ WYSZCZEGÓLNIENIE } & \multicolumn{16}{|c|}{ TERMINY (TYGODNIE) } \\
\hline & 3 & 4 & 5 & 6 & 7 & 8 & 9 & 10 & 11 & 12 & 13 & 14 & 15 & 16 & 17 & 18 \\
\hline Produkt A & & & & & & & & 1800 & & & & 650 & & & & 600 \\
\hline Produkt B & & & & & & & & 700 & & & & 460 & & & & 310 \\
\hline Produkt C & & & & & & & & 850 & & & & 700 & & & & 250 \\
\hline Moduł D & & & & & 250 & & & & & & 400 & & & & & \\
\hline Moduł E & & & & & & & & 450 & & & & 280 & & & & 320 \\
\hline Element F & & & & & & & & 170 & & & & 330 & & & & 150 \\
\hline Element $\mathrm{G}$ & & & 300 & & & & & & & & 250 & & & & & \\
\hline
\end{tabular}

Tabela 2 przedstawia stan zapasów przedsiębiorstwa poszczególnych wyrobów, modułów i elementów na tydzień pierwszy oraz siódmy. Służą one do obliczenia zapotrzebowania netto, które jest definiowane jako różnica zapotrzebowania brutto oraz zapasu dysponowanego.

Tabela 2

Stan zapasów przedsiębiorstwa

\begin{tabular}{||l|c|c|c|c|c|c|c|c|c|c|c|c|c|c|c|c||}
\hline \hline \multicolumn{10}{|c||}{ GLÓWNY ZBIÓR ZAPASÓW } \\
\hline \multirow{2}{*}{ WYSZCZEGÓLNIENIE } & \multicolumn{10}{|c||}{ TERMINY (TYGODNIE) } \\
\cline { 2 - 3 } & 3 & 4 & 5 & 6 & 7 & 8 & 9 & 10 & 11 & 12 & 13 & 14 & 15 & 16 & 17 & 18 \\
\hline Produkt A & & 70 & & & & & & & 30 & & & 250 & & & & \\
\hline Produkt B & 200 & & & & & & & 80 & & & 120 & & & & \\
\hline Produkt C & 50 & & & & & & & 20 & & & 340 & & & & \\
\hline Moduł D & 100 & & & & & & & 30 & & & 90 & & & & \\
\hline Moduł E & 70 & & & & & & & 70 & & & 500 & & & & \\
\hline Element F & 170 & & & & & & & 50 & & & 3400 & & & & \\
\hline Element G & 400 & & & & & & & 80 & & & 3200 & & & & \\
\hline \hline
\end{tabular}


Tabela 3 prezentuje czasy realizacji dostaw dla wyrobów, modułów i elementów, które umożliwiają określenie dokładnego momentu, tak aby zapewnić ciągłość produkcji i efektywne wykorzystanie dostępnych zasobów.

Tabela 3

\section{Czasy realizacji dostaw}

\begin{tabular}{||l|c|}
\hline \multicolumn{2}{|c|}{ CZAS REALIZACJI ZAMÓWIENIA } \\
\hline Produkt A & 2 \\
\hline Produkt B & 2 \\
\hline Produkt C & 2 \\
\hline Moduł D & 1 \\
\hline Moduł E & 1 \\
\hline Element F & 1 \\
\hline Element G & 1 \\
\hline
\end{tabular}

W tabeli 4 poniżej został przedstawiony plan potrzeb materiałowych (MRP), do sporządzenia którego wykorzystano dane zestawione w tabelach 1-3. Do obliczenia zapotrzebowania brutto wykorzystano opracowaną powyżej metodykę opisu charakterystyczną dla struktury wyrobów A, B i C wykazujących modułowość. Metodyka ta ma zastosowanie do opisu modułów oznaczonych jako D-1 oraz E-2 oraz elementów określanych jako F oraz $\mathrm{G}$, a zatem odnosi się do składowych umieszczanych na poziomach 1-3 struktury wyrobu (por. rys. 1, 2 i 3 ).

Przedstawiony plan potrzeb materiałowych został wykonany dla horyzontu czasowego obejmującego przedział od 3-18 tygodni. Zapotrzebowanie brutto na wyroby A i B zostało złożone w tygodniach 7-18. Po uwzględnieniu czasów realizacji dostaw i czasów montażu wygenerowane zamówienia wewnętrzne w rzeczywistości objęły przedział czasu 1-4 tygodni. Jest to związane z tzw. planowaniem wstecznym oraz listą materiałową (ang. bill of material) odniesioną każdorazowo do struktury wyrobu. 


\section{Czasy realizacji dostaw}

\begin{tabular}{|c|c|c|c|c|c|c|c|c|c|c|c|c|c|c|c|c|}
\hline \multicolumn{17}{|c|}{ MRP } \\
\hline Terminy (tygodnie) & 3 & 4 & 5 & 6 & 7 & 8 & 9 & 10 & 11 & 12 & 13 & 14 & 15 & 16 & 17 & 18 \\
\hline Produkt A - zapotrzebowanie brutto & & & & & & & & 1800 & & & & 650 & & & & 600 \\
\hline Zapas dysponowany & & 70 & 70 & 70 & 70 & 70 & 70 & 70 & 30 & 30 & 30 & 280 & & & & \\
\hline Zapotrzebowanie netto & & & & & & & & 1730 & & & & 370 & & & & 600 \\
\hline Zamówienie (zlecenie produkcyjne) & & & & & & 1730 & & & & 370 & & & & 600 & & \\
\hline Produkt B - zapotrzebowanie brutto & & & & & & & & 700 & & & & 460 & & & & 310 \\
\hline Zapas dysponowany & & 200 & 200 & 200 & 200 & 200 & 200 & 200 & 80 & 80 & 80 & 200 & & & & \\
\hline Zapotrzebowanie netto & & & & & & & & 500 & & & & 260 & & & & 310 \\
\hline Zamówienie (zlecenie produkcyjne) & & & & & & 500 & & & & 260 & & & & 310 & & \\
\hline Produkt C - zapotrzebowanie brutto & & & & & & & & 850 & & & & 700 & & & & 250 \\
\hline Zapas dysponowany & & 50 & 50 & 50 & 50 & 50 & 50 & 50 & 20 & 20 & 20 & 360 & & & & \\
\hline Zapotrzebowanie netto & & & & & & & & 800 & & & & 340 & & & & 250 \\
\hline Zamówienie (zlecenie produkcyjne) & & & & & & 800 & & & & 340 & & & & 250 & & \\
\hline Produkt D - zapotrzebowanie brutto & & & & & 250 & 3030 & & & & 970 & 400 & & & 1160 & & \\
\hline Zapas dysponowany & & 100 & 100 & 100 & 100 & & & & 30 & 30 & & 90 & 90 & 90 & & \\
\hline Zapotrzebowanie netto & & & & & 150 & 3030 & & & & 940 & 400 & & & 1070 & & \\
\hline Zamówienie (zlecenie produkcyjne) & & & & 150 & 3030 & & & & 940 & 400 & & & 1070 & & & \\
\hline Produkt E - zapotrzebowanie brutto & & & & 300 & 6060 & 4460 & & 450 & 1880 & 2060 & & 280 & 2140 & 1820 & & 320 \\
\hline Zapas dysponowany & & 70 & 70 & 70 & & & & & 70 & & & 500 & 220 & & & \\
\hline Zapotrzebowanie netto & & & & 230 & 6060 & 4460 & & 450 & 1810 & 2060 & & & 1920 & 1820 & & 320 \\
\hline Zamówienie (zlecenie produkcyjne) & & & 230 & 6060 & 4460 & & 450 & 1810 & 2060 & & & 1920 & 1820 & & 320 & \\
\hline Produkt F - zapotrzebowanie brutto & & & 230 & 6360 & 10520 & 11520 & 450 & 1980 & 3940 & 4520 & & 2250 & 3960 & 4760 & 320 & 150 \\
\hline Zapas dysponowany & & 170 & 170 & & & & & & 50 & & & 3400 & 1150 & & & \\
\hline Zapotrzebowanie netto & & & 60 & 6360 & 10520 & 11520 & 450 & 1980 & 3890 & 4520 & & & 2810 & 4760 & 320 & 150 \\
\hline Zamówienie (zlecenie produkcyjne) & & 60 & 6360 & 10520 & 11520 & 450 & 1980 & 3890 & 4520 & & & 2810 & 4760 & 320 & 150 & \\
\hline Produkt G - zapotrzebowanie brutto & & & 990 & 18480 & 19440 & 4260 & 1350 & 5430 & 8060 & 1880 & 250 & 5760 & 7600 & 1450 & 960 & \\
\hline Zapas dysponowany & & 400 & 400 & & & & & & 80 & & & 3200 & & & & \\
\hline Zapotrzebowanie netto & & & 590 & 18480 & 19440 & 4260 & 1350 & 5430 & 7980 & 1880 & 250 & 2560 & 7600 & 1450 & 960 & \\
\hline Zamówienie (zlecenie produkcyjne) & & 590 & 18480 & 19440 & 4260 & 1350 & 5430 & 7980 & 1880 & 250 & 2560 & 7600 & 1450 & 960 & & \\
\hline & & & & SkóWNY & HARMOI & DGRAM & PRODUI & CII & & & & & & & & \\
\hline
\end{tabular}

\section{Podsumowanie}

Celem niniejszego artykułu było opracowanie metodyki opisu dla wyrobów o strukturze modułowej oraz jej zastosowanie do harmonogramowania produkcji. Planowany cel został osiągnięty. Artykuł ukazuje, w jaki sposób należy zaplanować produkcję na wyroby o charakterystyce modułowej oraz określić moment ich zamówienia tak, aby zachować ciągłość i rytmiczność procesu wytwórczego. Jest to niezwykle ważne z punktu widzenia terminowego wykonania zamówień zewnętrznych (popytu niezależnego), a zatem wpływa na niezawodność realizacji dostaw. Zaprezentowana metodyka postępowania eliminuje błędy, zmniejsza poziom utrzymywanych zapasów, umożliwia pełną kontrolę poszczególnych etapów produkcji, usprawnia wykorzystanie dostępnych zasobów oraz synchronizuje procesy zamawiania i dostarczania materiałów z potrzebami produkcyjnymi. Metodyka postępowania została opracowana w 1957 r. przez APICS (American Production and Inventory Control Society), jej szczególny rozwój przypadł na lata siedemdziesiąte i osiemdziesiąte XX wieku. Jest dedykowana dla popytu zmiennego, charakteryzującego się nieregularnością, a przedsiębiorstwo produkcyjne wytwarza wyroby na skalę masową. $Z$ tego powodu w pierwszej kolejności należy ją odnieść do produkcji 
seryjnej lub potokowej, w drugiej do produkcji jednostkowej lub kombinacji wspomnianych powyżej rodzajów.

\section{Literatura}

1. Bozarth C., Handfield R.B.: Wprowadzenie do zarządzania operacjami i łańcuchem dostaw. Helion, Gliwice 2007.

2. Krawczyk S. (red.): Logistyka. Teoria i praktyka. t. 2. Difin, Warszawa 2011.

3. Niziński S., Żurek J.: Logistyka ogólna. WKiÆ, Warszawa 2011.

4. Nowakowski T.: Niezawodność systemów logistycznych. OWPW, Wrocław 2011.

5. Nowakowski T.: Reliability model of combined transportation system. [w:] Probabilistic Safety Assessment and Management. Spitzer C., Schmocker U., Dang V.N. (red.). Springer, London 2004.

6. Skowronek Cz., Sarjusz-Wolski Z.: Logistyka w przedsiębiorstwie. PWE, Warszawa 2012.

7. Śliwczyński B.: Planowanie logistyczne. ILiM, Poznań 2008.

8. Tomaszewska J., Woch M., Zieja M.: Analysis of the time between failures of aircrafts, 2nd International Conference on System Reliability and Safety, ICSRS 2017, Volume 2018-January, 29 January 2018.

9. Ważny M., Stepień S., Zieja M.: Outline of a method for estimating the durability of components or device assemblies while maintaining the required reliability level, Eksploatacja i Niezawodność, Volume 20, Issue 2, 2018.

10. Werbińska-Wojciechowska S.: Time resource problem in Logistics systems dependability modeling. Eksploatacja i Niezawodność - Maintenance and Reliability, 15(4), 2013.

11. Zięba M., Ziółkowski J.: System planowania potrzeb materiałowych (MRP) w przedsiębiorstwie produkcyjnym. Biuletyn Wojskowej Akademii Technicznej, nr 3/2012.

12. Żurek J., Zieja M., Ziółkowski J.: Reliability of supplies in a manufacturing enterprise. Safety and Reliability - Theory and Applications, Taylor \& Francis Group, London 2018. 